\title{
Tumor growth reduction is regulated at the gene level in Walker 256 tumor-bearing rats supplemented with fish oil rich in EPA and DHA
}

\author{
G. Borghetti, R.K. Yamazaki, I. Coelho, D.C.T. Pequito, D.L. Schiessel, M. Kryczyk, R. Mamus, \\ K. Naliwaiko and L.C. Fernandes \\ Departamento de Fisiologia, Setor de Ciências Biológicas, Universidade Federal do Paraná, Curitiba, PR, Brasil
}

\begin{abstract}
We investigated the effect of fish oil (FO) supplementation on tumor growth, cyclooxygenase 2 (COX-2), peroxisome proliferator-activated receptor gamma (PPAR $\gamma$ ), and RelA gene and protein expression in Walker 256 tumor-bearing rats. Male Wistar rats (70 days old) were fed with regular chow (group W) or chow supplemented with $1 \mathrm{~g} / \mathrm{kg}$ body weight FO daily (group WFO) until they reached 100 days of age. Both groups were then inoculated with a suspension of Walker 256 ascitic tumor cells $\left(3 \times 10^{7}\right.$ cells $\left./ \mathrm{mL}\right)$. After 14 days the rats were killed, total RNA was isolated from the tumor tissue, and relative mRNA expression was measured using the $2^{-\Delta \Delta C T}$ method. FO significantly decreased tumor growth $(\mathrm{W}=13.18 \pm 1.58 \mathrm{vs}$ $\mathrm{WFO}=5.40 \pm 0.88 \mathrm{~g}, \mathrm{P}<0.05)$. FO supplementation also resulted in a significant decrease in $\mathrm{COX}-2(\mathrm{~W}=100.1 \pm 1.62$ vs $\mathrm{WFO}=59.39 \pm 5.53, \mathrm{P}<0.001)$ and PPAR $\gamma(\mathrm{W}=100.4 \pm 1.04$ vs $\mathrm{WFO}=88.22 \pm 1.46, \mathrm{P}<0.05)$ protein expression. Relative mRNA expression was $\mathrm{W}=1.06 \pm 0.022$ vs $\mathrm{WFO}=0.31 \pm 0.04(\mathrm{P}<0.001)$ for $\mathrm{COX}-2, \mathrm{~W}=1.08 \pm 0.02$ vs $\mathrm{WFO}=0.52 \pm 0.08$ $(\mathrm{P}<0.001)$ for $\mathrm{PPAR} \gamma$, and $\mathrm{W}=1.04 \pm 0.02$ vs $\mathrm{WFO}=0.82 \pm 0.04(\mathrm{P}<0.05)$ for RelA. FO reduced tumor growth by attenuating inflammatory gene expression associated with carcinogenesis.
\end{abstract}

Key words: Cancer; Fish oil; Gene expression

\section{Introduction}

Several studies have reported the anti-inflammatory properties of $n-3$ polyunsaturated fatty acids (PUFAs), their involvement in the prevention of some chronic diseases, and their effects on cancer $(1,2)$. Changes in dietary fatty acid consumption, particularly in Western diets, cause an increase in the n-6:n-3 PUFA ratio. This change leads to unbalanced production of eicosanoids, which has been associated with the development of inflammatory conditions $(2,3)$. We previously reported that dietary supplementation with fish oil (FO), rich in n-3 PUFAs eicosapentaenoic acid (EPA) and docosahexaenoic acid (DHA), reduced tumor growth and cachexia in Walker 256 tumor-bearing rats (4-6). FO supplementation significantly enhanced the tumor content of n-3 PUFAs, with diminution of the n-6:n-3 ratio and reduction of cyclooxygenase-2 (COX-2) expression and prostaglandin $\mathrm{E}_{2}\left(\mathrm{PGE}_{2}\right)$ concentration in the plasma. These changes were associated with increased apoptosis and lipoperoxidation in the tumor tissue (6). Although all these findings might explain many of the anti-tumor actions of n-3 PUFA, eicosanoidindependent actions including EPA and DHA effects on transcription factors regulating inflammatory gene expression cannot be ruled out. It has been suggested that the high amount of n-3 PUFAs or shift in the $n-6: n-3$ ratio may attenuate the expression of important genes related to inflammation (3). n-3 PUFA can activate several transcription factors through signaling pathways that alter the expression of inflammatory genes $(7,8)$. So far, the molecular mechanisms involved are not fully understood, and it has been proposed that multiple mechanisms contribute to the effects of n-3 PUFA on cancer (9).

COX-1 and COX-2 are enzymes that catalyze the production of prostaglandins and thromboxanes from arachidonic acid (1). COX-1 is distributed and constitutively expressed in most cells and tissues. In contrast, COX-2 mRNA can be induced by inflammatory and 
proliferative stimuli. Although COX-2 induction is required during pathophysiological states, constitutive COX-2 activity is detected in brain, kidney, and the female reproductive tract $(10)$.

Peroxisome proliferator-activated receptor gamma (PPAR $\gamma$ ) is a ligand-activated transcription factor belonging to the nuclear hormone receptor family (PPARs $\alpha, \beta / \delta$, and $\gamma$ ) (1). Some studies have suggested that PPAR $\gamma$ regulates signal transduction pathways that lead to cell differentiation and inhibition of cell proliferation in several groups of carcinoma. In addition, it may play a role in the inflammatory response $(1,11)$.

The nuclear factor kappa B (NFkB) family includes members of the Rel family, including p50 (NFKB1), p52 (NF $\kappa$ B2), c-Rel, v-Rel, RelA (p65), and RelB. Their activation has been linked to a broad variety of proinflammatory and proangiogenic stimuli (12). In addition, $N F_{\kappa B}$ has been associated with inflammation and immunity in cancer development (7).

Here we hypothesize that tumor growth reduction shown in Walker 256 tumor-bearing rats supplemented with $\mathrm{FO}$ is also regulated at the gene level. The objective of this study was to investigate the effects of $\mathrm{FO}$ supplementation on COX-2, PPAR $\gamma$, and RelA gene expression in Walker 256 tumor-bearing rats.

\section{Material and Methods}

\section{Animals and study design}

All experimental procedures were carried out in accordance with the ethical principles established by the Experimental Brazilian Council (COBEA) and approved by the local Ethics Animal Experiment Committee (certificate number 344). Male, 70-day-old Wistar rats were housed under controlled temperature $\left(23^{\circ} \mathrm{C}\right)$, humidity $(50 \pm 5 \%)$ and a 12:12-h light-dark cycle, and received a regular chow diet (Nutrilab CR1, Nuvital Nutrients Ltda., Brazil) ad libitum. The rats were divided into two groups, one was fed regular chow only (W group) and the other was fed the same regular chow supplemented with oral FO (WFO group). FO composition of the supplement was determined by HPLC to contain (\% fatty acid): $4.8 \%$ lauric, $9.9 \%$ miristic, $15 \%$ palmitic, $1.9 \%$ stearic, $17 \%$ palmitoleic, $10.6 \%$ oleic, $11.6 \%$ linoleic, $0.7 \%$ arachidonic, $23.8 \%$ EPA, and $19.8 \%$ DHA. The FO capsules were kindly donated by the Herbarium Foundation for Health and Research (Curitiba, PR, Brazil). The WFO group received the oil at a dose of $1 \mathrm{~g} / \mathrm{kg}$ body weight daily, given orally using a microliter pipette, until they reached 100 days of age. All animals were then inoculated in the right flank with a $1-\mathrm{mL}$ sterile suspension of Walker 256 ascitic tumor cells $\left(3 \times 10^{7}\right.$ cells $/ \mathrm{mL}$ ). On the 14 th day after tumor inoculation, they were killed, the tumor mass was removed, and different samples of the same tumor were used for experimental analyses.

\section{Immunoblotting}

Protein concentration in the tumor tissue was determined using the Bradford method. Tumor tissue samples (100 $\mathrm{mg}$ ) were homogenized in radioimmune precipitation assay lysis buffer, and samples $(45 \mu \mathrm{g})$ were loaded to a $10 \%$ SDS polyacrylamide gel for electrophoresis and then transferred to nitrocellulose membranes using a semi-dry blotter apparatus (Bio-Rad, USA). The membranes were incubated overnight at $4{ }^{\circ} \mathrm{C}$ with the following individual antibodies: anti-COX-2 (72 kDa), anti-PPAR $\gamma(67 \mathrm{kDa})$, anti-RelA (p65; $65 \mathrm{kDa})$, and anti- $\beta$-actin (43 kDa) at a $1: 1000$ dilution (Santa Cruz Biotechnology, USA), and then for $2 \mathrm{~h}$ with a secondary antibody-conjugated rabbit horseradish peroxidase (Pierce, USA) at a 1:6000 dilution. The West Pico Chemoluminescent substrate (Super Signal System Pierce, USA) was used, and membranes were exposed to Kodak film before development. The resulting bands were analyzed and quantified by the Image $J^{\mathbb{R}}$ software (USA), with anti- $\beta$-actin as a loading control.

\section{Quantitative real-time PCR (qPCR)}

Fresh tumor tissue samples (100 mg) were homogenized and total RNA was isolated using Trizol Reagent (Invitrogen, USA) according to the manufacturer's instructions. RNA concentration and purity were checked with a spectrophotometer (Nanodrop ND 1000, Thermo Scientific, USA). RNA samples with 260/280 and 260/230 nm adsorbance ratios $>1.9$ were used. The integrity of total RNA was measured by $0.8 \%$ agarose gel electrophoresis. Reverse transcription was performed with the Improm II RT System (Promega, USA) according to the manufacturer's protocol. qPCRs were performed in Rotor Gene 6000 (Qiagen, USA) using SYBR Green Mix, following the manufacturer's instructions. PCRs were performed with cDNA samples $(5 \mathrm{ng})$ in triplicate under the following conditions: $95^{\circ} \mathrm{C}$ for $5 \mathrm{~min}$, followed by 35 cycles of $\left(95^{\circ} \mathrm{C}\right.$ for $15 \mathrm{~s}, 60^{\circ} \mathrm{C}$ for $15 \mathrm{~s}$, and $72^{\circ} \mathrm{C}$ for $\left.15 \mathrm{~s}\right)$. The primers were designed following criteria for real-time PCR and were synthesized by Prodimol, Brazil. The sequences were as follows: 5'-CAGGCCAGACTTTGTTGGAT-3' (sense) and 5'-CCACTTTCGCTGATGACAC-3' (antisense) 116 bp for the hypoxanthine-guanine phosphoribosyltransferase (HPRT) reference gene; 5'-ATCAGGTCATCGGTGGA GAG-3' (sense) and 5'-GCACCAGACCAAAGACTTCC-3' (antisense) 126 bp for COX-2; 5'-GCCCTTTGGTGACTTT ATGG-3' (sense) and 5'-GGCGGTCTCCACTGAGAATA-3' (antisense) $119 \mathrm{bp}$ for PPAR $\gamma$; and 5'-ACTTGCCAGAC ACAGACGAT-3' (sense) and 5'-GGGTTCAGTTGGTC CATTG-3' (antisense) 145 bp for RelA. Validation of the reference gene (HPRT) and the amplification efficiencies of targets and reference were performed (13); the fold-change for each sample was analyzed by the $2^{-\Delta \Delta C T}$ method.

\section{Statistical analysis}

Data are reported as means \pm SE. Statistical analysis was performed with the two-tailed Student $t$-test using the 
Prism Software (GraphPad, USA). The value $\mathrm{P}<0.05$ was taken to indicate statistical significance.

\section{Results}

We examined the effect of FO supplementation on tumor growth and protein and relative mRNA expression of COX-2, PPAR $\gamma$, and RelA in tumor tissue from Walker 256 tumor-bearing rats. FO supplementation resulted in a significant decrease (2.4-fold) in tumor weight in the WFO group compared with the $\mathrm{W}$ group $(\mathrm{W}=13.18 \pm 1.58 \mathrm{vs}$ $\mathrm{WFO}=5.40 \pm 0.88 \mathrm{~g} ; \mathrm{P}<0.05)$. Protein expression of COX-2 and PPAR $\gamma$ in tumor tissue from rats fed regular chow (W) and FO supplemented are shown in Figure 1. FO supplementation resulted in significant decreases in COX-2 $(\mathrm{P}<0.001)$ and in PPAR $\gamma(\mathrm{P}<0.05)$ expression. The change in RelA protein expression was not significant in the WFO group compared to the W group (data not shown). FO supplementation also resulted in significant decreases in the relative expression of mRNA in tumor tissue (Figure 2) of 3.4-fold for COX-2 (P<0.001), 2-fold for PPAR $\gamma(P<0.001)$, and 1.2-fold for RelA $(P<0.05)$ in the WFO compared to the $W$ group.

\section{Discussion}

Our previous research demonstrated that FO supplementation decreases tumor growth and cancer cachexia in Walker 256 tumor-bearing rats (4-6). Several mechanisms for suppression of tumor growth in Walker 256 tumor-bearing rats by $n-3$ PUFA have been proposed. The effects of n-3 PUFAs on both cell proliferation and apoptosis are exerted through decreases in $P E_{2}$ production by the COX-2 pathway (6). It has also been shown that a high level of COX-2 induces production of proangiogenic factors in many cancer cells (14). COX-2 is believed to exert tumor-promoting effects in regulation of the cell survival and signaling pathways that are involved with tumor cell initiation, transformation, invasiveness, and metastasis $(15,16)$. It has also been shown that $n-3$

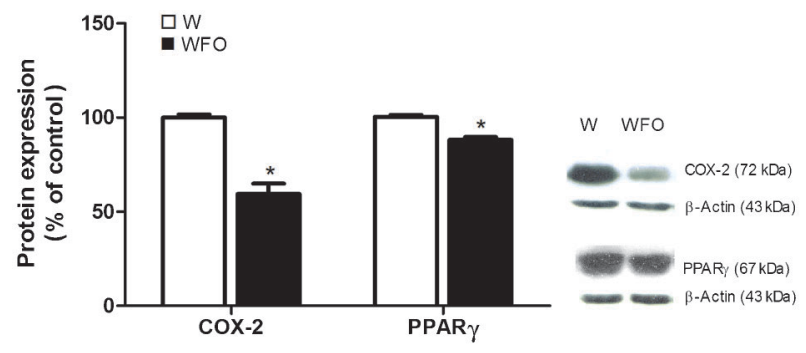

Figure 1. Protein expression of COX-2 and PPAR $\gamma$ in tumor tissue from rats fed a regular chow diet $(\mathrm{W})$ or a regular chow diet supplemented with fish oil (WFO). Anti- $\beta$-actin was used as a loading control. Data are reported as means \pm SE of $n=7(W)$ and $n=8$ (WFO) rats from three independent experiments. ${ }^{*} \mathrm{P}<0.05$ vs $\mathrm{W}$ (Student $t$-test).

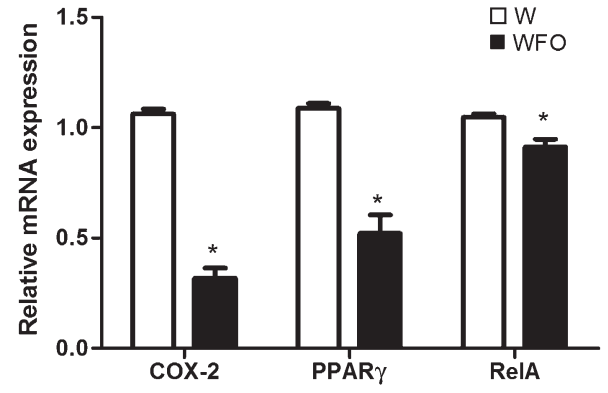

Figure 2. Relative mRNA expression of COX-2, PPAR $\gamma$ and RelA in tumor tissue from rats fed a regular chow diet (W) or a regular chow diet supplemented with fish oil (WFO). Fold-change compared to $\mathrm{W}$ was calculated using the $2^{-\Delta \Delta C T}$ method. Data are reported as means \pm SE of $n=8(W)$ and $n=9$ (WFO) rats from three independent experiments. ${ }^{*} \mathrm{P}<0.05$ vs $\mathrm{W}$ (Student $t$-test).

PUFA has anti-angiogenic and anti-inflammatory effects by attenuation of important molecules, such as COX-2, $\mathrm{PGE}_{2}$, and the NFKB family (14).

The mechanisms that explain, in part, the antiinflammatory effects of n-3 PUFA are related to the decrease in expression of genes related to inflammation, including $\mathrm{NF} \kappa \mathrm{B}$, proinflammatory cytokines, and genes involved in eicosanoid synthesis $(7,17)$. Studies of FO supplementation in healthy humans suggest that a shift in the $n-6: n-3$ PUFA ratio is likely to affect inflammatory responses, which may be related to regulation of expression of signal transduction genes (8). Dietary supplementation with EPA and DHA can change the gene expression profiles of mononuclear cells, decreasing the expression of genes involved in inflammation and atherogenic pathways, eicosanoid synthesis, and hypoxia signaling (17). It has been reported that PPARs are involved in the beneficial effects of $n-3$ PUFA leading to gene expression via PPAR activation (1). Studies of human gastric cancer showed upregulation of PPAR $\gamma$, suggesting its participation in gastric carcinogenesis (11). Furthermore, it has been suggested that n-3 PUFA is also related to microRNA expression, but the mechanisms remain unknown (18).

Some important steps should be followed in experimental protocols to analyze relative gene expression using the $2^{-\Delta \Delta C T}$ method. The efficiency of target and reference gene amplification as well as the selection of a suitable internal control gene should be validated to avoid inconsistent results $(13,19)$. Tumor growth reduction from FO-supplemented rats was accompanied by a significant decrease in the protein and mRNA expression of COX-2 and PPAR $\gamma$ as well as in mRNA expression of RelA, but the change in the RelA protein was not significant. The disagreement between mRNA and protein expression is due to the complex mechanisms of gene expression control that include the regulation of the genetic code and the co- and post-translational modifications (19). 
Upregulation of PPAR $\gamma$ expression is frequent in a variety of malignant tumors. However, its exact role in tumor cell growth is still unclear. PPARs are transcription factors that regulate gene expression and act as intracellular receptors by binding lipid molecules, such as n-3 PUFA. It is probable that $n-3$ PUFA acts as a transducing signal. However, it is not possible to relate the level of expression to the activity of PPAR $\gamma$. In this study, we suggest that PPAR $\gamma$ could be the link between n-3 PUFA and tumor growth. Further studies are necessary to determine the relationship of n-3 PUFA with other genes involved in cell proliferation of tumors as well as cell death.

It has been suggested that multiple molecular mechanisms may contribute to the protective effects of

\section{References}

1. Chene G, Dubourdeau M, Balard P, Escoubet-Lozach L, Orfila $C$, Berry $A$, et al. $n-3$ and $n-6$ polyunsaturated fatty acids induce the expression of COX-2 via PPARgamma activation in human keratinocyte HaCaT cells. Biochim Biophys Acta 2007; 1771: 576-589, doi: 10.1016/j.bbalip.2007.02.014.

2. Riediger ND, Othman RA, Suh M, Moghadasian MH. A systemic review of the roles of n-3 fatty acids in health and disease. J Am Diet Assoc 2009; 109: 668-679, doi: 10.1016/ j.jada.2008.12.022

3. Calder PC. Polyunsaturated fatty acids and inflammation. Prostaglandins Leukot Essent Fatty Acids 2006; 75: 197202, doi: 10.1016/j.plefa.2006.05.012.

4. Pinto JA Jr, Folador A, Bonato SJ, Aikawa J, Yamazaki RK, Pizato $\mathrm{N}$, et al. Fish oil supplementation in F1 generation associated with naproxen, clenbuterol, and insulin administration reduce tumor growth and cachexia in Walker 256 tumor-bearing rats. J Nutr Biochem 2004; 15: 358-365, doi: 10.1016/j.jnutbio.2004.02.002.

5. Pizato N, Bonatto S, Yamazaki RK, Aikawa J, Nogata C, Mund RC, et al. Ratio of n-6 to n-3 fatty acids in the diet affects tumor growth and cachexia in Walker 256 tumorbearing rats. Nutr Cancer 2005; 53: 194-201, doi: 10.1207/ s15327914nc5302_8.

6. Mund RC, Pizato N, Bonatto S, Nunes EA, Vicenzi T, Tanhoffer $\mathrm{R}$, et al. Decreased tumor growth in Walker 256 tumor-bearing rats chronically supplemented with fish oil involves COX-2 and PGE2 reduction associated with apoptosis and increased peroxidation. Prostaglandins Leukot Essent Fatty Acids 2007; 76: 113-120, doi: 10.1016/j.plefa.2006.11.008.

7. Chapkin RS, Kim W, Lupton JR, McMurray DN. Dietary docosahexaenoic and eicosapentaenoic acid: emerging mediators of inflammation. Prostaglandins Leukot Essent Fatty Acids 2009; 81: 187-191, doi: 10.1016/j.plefa.2009.05.010.

8. Weaver KL, Ivester P, Seeds M, Case LD, Arm JP, Chilton $\mathrm{FH}$. Effect of dietary fatty acids on inflammatory gene expression in healthy humans. J Biol Chem 2009; 284: 15400-15407, doi: 10.1074/jbc.M109.004861.

9. Chapkin RS, Seo J, McMurray DN, Lupton JR. Mechanisms by which docosahexaenoic acid and related fatty acids reduce colon cancer risk and inflammatory disorders of the intestine. Chem Phys Lipids 2008; 153: 14-23, doi: 10.1016/ n-3 PUFA against cancer, with its pleiotropic action becoming more evident (9). Although the molecular mechanisms involved in mRNA regulation are not fully understood, our data suggest that FO may exert its effects by attenuating the expression of inflammatory genes that are associated with carcinogenesis. To our knowledge, this is the first report describing gene expression of COX-2, PPAR $\gamma$, and RelA in Walker 256 tumor-bearing rats supplemented with FO.

\section{Acknowledgments}

Research supported by the Herbarium Foundation, CAPES, and CNPq. j.chemphyslip.2008.02.011.

10. Rouzer CA, Marnett LJ. Cyclooxygenases: structural and functional insights. J Lipid Res 2009; 50 (Suppl): S29-S34, doi: 10.1194/Jr.R800042-JLR200.

11. Yao L, Liu F, Sun L, Wu H, Guo C, Liang S, et al. Upregulation of PPARgamma in tissue with gastric carcinoma. Hybridoma 2010; 29: 341-343, doi: 10.1089/hyb.2010.0013.

12. Spencer L, Mann C, Metcalfe M, Webb M, Pollard C, Spencer D, et al. The effect of omega-3 FAs on tumour angiogenesis and their therapeutic potential. Eur $\mathrm{J}$ Cancer 2009; 45: 2077-2086, doi: 10.1016/j.ejca.2009.04.026.

13. Livak KJ, Schmittgen TD. Analysis of relative gene expression data using real-time quantitative PCR and the 2(-Delta Delta C(T)) method. Methods 2001; 25: 402-408, doi: 10.1006/meth.2001.1262.

14. Massaro M, Scoditti E, Carluccio MA, Montinari MR, De Caterina R. Omega-3 fatty acids, inflammation and angiogenesis: nutrigenomic effects as an explanation for antiatherogenic and anti-inflammatory effects of fish and fish oils. J Nutrigenet Nutrigenomics 2008; 1: 4-23, doi: 10.1159/ 000109871.

15. de Visser KE, Eichten A, Coussens LM. Paradoxical roles of the immune system during cancer development. Nat Rev Cancer 2006; 6: 24-37, doi: 10.1038/nrc1782.

16. Bouzourene $H$, Yan $P$, Sandmeier D, Zouhair A, Matter M, Vuilleumier $\mathrm{H}$, et al. The role of COX-2 in rectal cancer treated with preoperative radiotherapy. Virchows Arch 2008; 452: 499-505, doi: 10.1007/s00428-008-0606-9.

17. Bouwens M, van de Rest O, Dellschaft N, Bromhaar MG, de Groot LC, Geleijnse JM, et al. Fish-oil supplementation induces antiinflammatory gene expression profiles in human blood mononuclear cells. Am J Clin Nutr 2009; 90: 415-424, doi: 10.3945/ajen.2009.27680.

18. Davidson LA, Wang N, Shah MS, Lupton JR, Ivanov I, Chapkin RS. n-3 Polyunsaturated fatty acids modulate carcinogen-directed non-coding microRNA signatures in rat colon. Carcinogenesis 2009; 30: 2077-2084, doi: 10.1093/ carcin/bgp245.

19. Bustin SA, Benes V, Garson JA, Hellemans J, Huggett J, Kubista M, et al. The MIQE guidelines: minimum information for publication of quantitative real-time PCR experiments. Clin Chem 2009; 55: 611-622, doi: 10.1373/clinchem.2008.112797. 